Barnett Anthony (Orcid ID: 0000-0002-6733-3542)

Quach Jon (Orcid ID: 0000-0002-3055-3082)

Page 1

\author{
Predictors of learning outcomes for children \\ with and without chronic illness: An Australian \\ longitudinal study
}

\begin{abstract}
Honorary Research Fellow Tony Barnett ${ }^{1},{ }^{2}$, Doctor Rebecca Giallo ${ }^{1}$, Professor Margaret Kelaher ${ }^{4}$, Professor Sharon Goldfeld ${ }^{\mathbf{1}}{ }^{\mathbf{2}}$, Doctor Jon Quach $^{\mathbf{1}}{ }^{\mathbf{3}}$
\end{abstract}

\author{
${ }^{1}$ Murdoch Childrens Research Institute, Flemington Rd, Parkville, Victoria 3052 \\ 2Department of Paediatrics, University of Melbourne, Parkville. Victoria 3052 \\ ${ }^{3}$ Graduate School of Education, University of Melbourne, Parkville, Victoria 3052 \\ ${ }^{4}$ Centre for Health Policy, Melbourne School of Population and Global Health, \\ University of Melbourne, Carlton, VIC 3010, Australia
}

\begin{abstract}
Author Note
We acknowledge the following support for the authors. Support from the Australian National Health and Medical Research Career Development Fund for Sharon Goldfeld and Rebecca Giallo. Support from the Australian Research Council Discovery Early Career Researcher Award for Jon Quach. Support from the Royal Children's Hospital for Tony Barnett.
\end{abstract}

This is the author manuscript accepted for publication and has undergone full peer review but has not been through the copyediting, typesetting, pagination and proofreading process, which may lead to differences between this version and the Version of Record. Please cite this article as doi: $10.1111 /$ cch.12597

This article is protected by copyright. All rights reserved. 
[First Authors Last Name] Page 2

Corresponding author: Tony Barnett. Email: tonybar77@gmail.com Telephone: $+61422510951$

This article is protected by copyright. All rights reserved. 


\begin{abstract}
BACKGROUND: Chronically ill children are at increased risk of poor learning outcomes. Knowledge of the predictors of learning outcomes for this group of people is important to inform the development of education supports that stand the best chance of being effective. This study explored the child, family and school risk and protective factors during the child's transition to elementary school (aged 6-7 years) that were associated with learning outcomes when children were aged 10-11 years for both children with and without a chronic illness. METHODS: Data from the Longitudinal Study of Australian Children were used. Predictor variables were entered into separate multivariate regression models for children with and without a chronic illness.

RESULTS: The strongest predictors of learning outcomes were the child's approach to learning, a consistent parenting style and family socio-economic position, and were common for both children with and without a chronic illness but strongest for children with a chronic illness. CONCLUSION: A child's approach to learning and a consistent parenting style during the period of the child's transition to elementary school are important and potentially modifiable factors that are predictive of academic performance in later childhood. These factors are particularly relevant for children with a chronic illness, their parents/care-givers, teachers both hospital and school based, and paediatricians, and can be used to inform interventions.
\end{abstract}

Keywords: Chronic illness, Schools, Child development

This article is protected by copyright. All rights reserved. 


\section{Predictors of learning outcomes for children with and without chronic illness: An Australian longitudinal study}

\section{Introduction}

Up to $30 \%$ of children in developed countries have a chronic illness, which is commonly defined as an illness lasting more than 6 months with a slow progression and poor prognosis (AIHW, 2005). Childhood chronic illnesses include conditions such as asthma, cancer, Crohn's disease, diabetes, and cystic fibrosis. They bear both physical consequences and secondary psychological and educational consequences that have a significant impact on the individual's quality of life (Martinez \& Ercikan, 2009).

Research has shown that children with a chronic illness are at greater risk than their healthy peers, of worse learning and developmental outcomes both in the short and longer term (Martinez \& Ercikan, 2009; Maslow, Haydon, McRee, \& Halpern, 2012; Nasuuna, Santoro, Kremer, \& Silva, 2016; Wiesner, Vondracek, Capaldi, \& Porfeli, 2003). In a recent systematic meta-review, Lum and colleagues critiqued the available evidence examining the link between six chronic illnesses and children's and adolescents' school experiences and outcomes. They found that students with chronic illnesses, while demonstrating mixed results, often had worse school experiences and outcomes as compared to students without chronic illnesses (Lum et al., 2017). They suggest that, "An improved understanding of the factors that help to explain or mitigate this risk can help educators and health professionals deliver the most effective support". In this paper we aim to review, critique and build on what is empirically known about such risk and protective factors. 
While previous research has examined a range of predictors associated with child learning generally (Kyndt, Cascallar, \& Dochy, 2012; Li-Grining, Votruba-Drzal, Maldonado-Carreño, \& Haas, 2010; Roorda, Koomen, Spilt, \& Oort, 2011; Sektnan, McClelland, Acock, \& Morrison, 2010), knowledge about the risk and protective factors associated with the educational outcomes for children with chronic illnesses is more limited. Further, studies thus far have mainly been cross-sectional which, by design, lack a temporal aspect to support any claim of causality or direction of effect. In addition, studies have examined associations between a limited number of mostly non-modifiable demographic factors which, therefore, do not open avenues for intervention (Currie \& Stabile, 2006; Kuehni et al., 2012; Martinez \& Ercikan, 2009).

Among the few stronger longitudinal studies, Maslow et al. (2012) found school connectedness during adolescence was associated with college graduation among young adults with childhood-onset chronic illness. While Singh et al. (2015) in a study of 337 Canadian children with inflammatory bowel disease (IBD) found that socioeconomic status and mental health problems 6 months prior to or 6 months post-IBD diagnosis predicted grade 12 educational outcomes (English language arts and mathematics achievement). In addition, Champaloux and Young (2014) in the United States of America analyzed data from the National Longitudinal Survey of Youth and found that for youth who reported cancer, diabetes or epilepsy, the association between illness and completion of high school by age 21 was mediated by depressive symptoms, school absence and having repeated a grade. It is the only study that has investigated the influence of factors from across the child's socio-ecological spheres: individual, family, school and community. 
A better understanding of the risk and protective factors associated with educational outcomes is therefore warranted to inform evidence-based interventions that improve learning for children and young people with chronic illnesses. Furthermore, educational interventions that optimize learning opportunities in the early years may promote a more positive learning trajectory for children with chronic illnesses(Brinkman et al., 2013). To address this gap in our knowledge, the present study sought to identify for children with a chronic illness, the risk and protective factors from across the child's socio-ecological levels during their transition to elementary school that are predictive of their longer-term educational outcomes (when children were aged 10-11 years) who had participated in a large, nationally-representative, Australian population cohort study of children and their families. We included both children with and without chronic illnesses to allow us to identify patterns and unique predictors of educational functioning for children with chronic illnesses.

Specifically, we aimed to explore:

1. The risk and protective factors present during the child's transition to elementary school when children were aged 6-7 years, on their academic achievement at 10-11 years;

2. If the risk and protective factors differ for children with and without a chronic illness during the important and predictive period of children's transition to elementary school.

\section{Methods}

\section{Participants}

Data were drawn from the nationally-representative Growing Up in Australia: Longitudinal Study of Australian Children (LSAC) (Australian Institute of Family Studies, 2007). The 
sampling design and data collection methods have been described elsewhere (Soloff, Lawrence, \& Johnstone, 2005). The study was approved by the Australian Institute of Family Studies Ethics Committee. Briefly, LSAC employed a two-stage cluster sampling design to recruit two independent cohorts, the Baby cohort (B-cohort;recruited at 0-1 years) and the Kindergarten cohort (K-cohort; recruited at 4-5 years). In the first stage, postcodes (geographic postal areas) (except the most remote) were sampled after stratifying by state, and urban versus rural status, to ensure proportional representation based on residential location. In the second stage, all children born between March 1999 and February 2000 and enrolled in the Australian Medicare database, with which $98 \%$ of all four-year old Australian children are registered, were eligible to be approached. Children were randomly selected within each postcode to achieve a cohort aged 4 to 5 years at the Wave 1 (baseline) interview, with all birth months represented. Of the 8,391 families contacted in 2004 to participate, written informed consent was received from parents of 4,983 (59\%) children. Data collection occurred every 2 years. As such, Wave 2 of LSAC took place in 2006 when children were 6 to 7 years, with 4,464 (89.6\%) families remaining in the study. Wave 3 participants, from 2008, and their data are not included in our study as they are not relevant to the research questions as either predictor or outcome variables; the primary outcome for our study is four years from baseline for the K cohort. By Wave 4 in 2010 when the children were 10 to 11 years, $4103(82 \%)$ remained in the study. Retention was marginally lower for children with less highly educated parents and from non-English speaking backgrounds (Daraganova \& Sipthorp, 2011).

\section{Procedure}


At the data collection time points, trained researchers administered a face-to-face interview in the child's home with the primary caregiver/parent, as well as brief direct assessments with the children. In addition, written questionnaires were completed by the primary and secondary caregiver/parent and, wherever possible, the child's elementary school teacher.

\section{Measures}

Child chronic illness group; Waves 1 and 2: In both waves, child chronic illness was defined by the primary caregiver-reported question (normally mothers) at interview "Does Study Child have any medical conditions or disabilities that have lasted, or are likely to last, for six months or more?". Children who had a chronic illness at either Wave 1 or 2 were classified as having a chronic illness during the elementary school transition. The measure is directly derived from the Disability Module used by the Australian Bureau of Statistics to define national prevalence rates and inform policy development (Harper, 2010). In addition, the single question with some small variations has been widely used in western developed countries for measuring the prevalence of chronic health conditions and disabilities (EU-SILC 065, 2014; UK Office of National Statistics, 2015). In the LSAC study, if the primary caregiver answered "Yes" to the above question, they were then asked about the nature of the condition or disability (i.e. sight problems, difficulty learning or understanding, disfigurement or deformity, long-term effects or head injury).

The primary outcome was child learning outcomes at 10-11 years (Wave 4). This was measured using the mean Rasch score from the adapted version of the teacher-reported Academic Rating Scale from the Early Childhood Longitudinal Study (Rock \& Pollack, 2002). The measure 
consists of the two subscales for Language \& Literacy (11 items: e.g. The study child...Contributes relevant information to classroom discussions; The study child...Is able to write sentences with more than one clause.) and the Mathematical Thinking (9 items: e.g. The study child...Makes reasonable estimates of quantities; The study child...Counts change with two different types of coins). The possible range of scores was 1 to 5, with higher scores indicating greater learning proficiency. The fit and reliability of the sub-scales is very high. For full psychometric information see Rock and Pollack (2002).

The early predictors for child academic achievement were measured at Wave 2 when children were 6-7 years. Predictors were chosen a priori from within the LSAC data, informed by the conceptual model developed by O'Connor et al. (2015) (see Figure 1) and what are well understood to be important factors also from across the child's socio-ecological spheres (BrooksGunn, 2003; Duncan et al., 2007; Shonkoff \& Phillips, 2000). The conceptual model (Figure 1) takes into account the interrelated nature of four domains of a child's functioning, which are particularly relevant to children with special health care needs (SHCN). These domains of functioning are influenced by risk and protective factors at the individual, family and service system levels. These risk and protective factors and the child's functional status are likely to interact and shape school functioning and learning outcomes. The primary learning outcome used in our study has been described above. A full and detailed list of the proposed predictive risk and protective factors from across the socio-ecological levels used in this this study is provided in Table 1. These predictor variables were also measured at Wave 4 when children were 10-11 years as concurrent factors, as both potential predictors and confounders. 
Figure 1: Conceptual model of the relationship between special health care needs and children's school progress (O'Connor, Howell-Meurs, Kvalsvig, \& Goldfeld, 2015)

\section{Data Analysis}

Analyses were conducted using MPlus Version 7 (Muthén \& Muthén, 2011).

Demographic characteristics and potential predictor variables were summarized by using proportions for categorical variables and means and standard deviations for continuous variables. Predictor variables were entered into separate multivariate regression models for children with and without a chronic illness at two time-points. Firstly, multiple regression models were run to identify predictors present at school entry (age 6-7 years) for child learning outcomes four years later (age 10-11 years). Secondly, multiple regression models were run to identify predictors present at school entry while taking into account the influence of concurrent factors at 10-11 years. Risk factors found to be highly collinear were excluded from the multivariate analyses. All analyses were weighted using wave 1 sample weights to account for participants' unequal probability of selection into the sample, and the MPlus stratification and cluster options were applied to account for the complex survey design of LSAC. Results are presented as standardized beta weights with $95 \%$ confidence intervals.

\section{Results}

Characteristics of participants: children with and without a chronic illness

This article is protected by copyright. All rights reserved. 
Of the 4103 children still in the study at Wave 4, $4010(97.7 \%)$ had data pertaining to chronic illnesses. Overall, 987 (24.6\%) children had a chronic illness during the period of their transition to elementary school. The sample characteristics are presented in Table 2. Compared to those without a chronic illness, descriptive analyses found that those with a chronic illness were more likely to be male (62.2\% vs 47.5\%), from an English-speaking background (90\% vs $86.0 \%)$, be living in a sole parent family (13.7\% vs $10.4 \%)$, and have a lower socioeconomic position $(0.04$ vs $0.14,=<0.001)$. Their mothers are less likely to be in paid employment $(55.7 \%$ vs $63.6 \%)$ or to have completed secondary school (55.6\% vs $63.7 \%)$.

\section{Missing data and descriptive statistics}

In the final study sample, there was $<10 \%$ missing data for most study variables. Missing data were most common for the child's approach to learning (18\% and 19\% at 6-7 and 10-11 years, respectively) and student-teacher relationship (18\% and $19.5 \%$ at 6-7 and 10-11 years, respectively). These were replaced using the default option - Full Information Maximum Likelihood option in Mplus.

Independent samples ANOVAs were used to compare children with and without a chronic illness on each of the study variables. Children with a chronic illness were reported to have significantly more emotional and behavioural difficulties, a less positive approach to learning, more days absent from school, fewer out of home learning activities at age 10-11 years, and a less positive student-teacher relationship than children without a chronic illness. Finally, parents of children with a chronic illness reported significantly more parenting irritability/anger and psychological distress than parents of children without a chronic illness. 


\section{Predictors present at school entry (age 6-7 years) for child learning outcomes at age}

\section{0-11 years}

Multiple regression models with all predictors were fitted for both children with and without a chronic illness. For children with a chronic illness, the model containing the predictor variables in Table 3 significantly accounted for $40 \%$ of the variance in learning outcomes at age $10-11$ years $\left(\mathrm{R}^{2}=0.40, \mathrm{t}=13.07, \mathrm{p}<.001\right)$. The significant predictors of better learning outcomes were: fewer emotional and behavioural difficulties, having a better approach to learning, residing in a two-parent family, high socioeconomic position, high parental consistency, few in-home learning activities, and a less positive teacher-student relationship.

For children without a chronic illness, the model accounted for $26 \%$ of the variance in learning outcomes at age $10-11$ years $\left(\mathrm{R}^{2}=0.26, \mathrm{t}=11.76, \mathrm{p}<0.001\right)$. The significant predictors of better learning outcomes for this group of children were: having fewer emotional and behavioural difficulties, a better approach to learning, having a non-English first language, having few siblings, high socio-economic position, high parental consistency, few in-home learning activities, and a less positive teacher-student relationship.

\section{Predictors present at school entry (age 6-7 years) for child learning outcomes at age}

\section{0-11 years whilst accounting for concurrent factors at 10-11 years}

Multiple regression models with all predictors at age 6-7 plus concurrent predictors at 1011 years were fitted for both children with and without a chronic illness. For children with a chronic illness, the model containing the predictor variables in Table 4 significantly accounted for $55 \%$ of the variance in learning outcomes at age $10-11$ years $\left(\mathrm{R}^{2}=0.55, \mathrm{t}=21.56, \mathrm{p}<.001\right)$. The 
significant predictors of better learning outcomes were: being male, having fewer emotional and behavioural difficulties at 10-11 years, having a better approach to learning at both time points, high socioeconomic position, high parental consistency at 6-7 years, few in-home learning activities at 10-11 years, and a less positive teacher-student relationship at both time points. For children without a chronic illness, the model accounted for $40 \%$ of the variance in learning outcomes at age 10-11 years $\left(\mathrm{R}^{2}=0.40, \mathrm{t}=19.67, \mathrm{p}<.001\right)$. The significant predictors of better learning outcomes for this group of children were: being female, having a better approach to learning at both time points, having a non-English first language, having few siblings, high socio-economic position, parenting consistency at 6-7 years, having more out-of-home learning experiences at 10-11 years, fewer in-home learning activities at both time points, and a less positive teacher-student relationship at both time points.

\section{Discussion}

This is the first study to identify a broad range of risk and protective factors at the transition to elementary school associated with later learning outcomes for both children with and without a chronic illness when aged 10-11 years. In combination, the risk and protective factors identified at school entry (age 6-7 years), while accounting for the influence of concurrent factors, accounted for $55 \%$ and $41 \%$ of the variance in learning outcomes at age $10-11$ for children with and without chronic illness, respectively. Importantly, the risk and protective factors were largely similar for both populations of children. The strongest predictors were the family socio-economic position, the child's approach to learning and a consistent parenting style. Notably, children's approach to learning at age 6-7 remained predictive of learning outcomes at 
age 10-11 even after taking into account the influence of their concurrent approach to learning. For both groups, children's emotional and behaviour difficulties at age 6-7 years was also predictive of their learning outcomes at age 10-11, but this association dropped off once the influence of concurrent factors was taken in to account. Not surprisingly, emotional and behavioural difficulties at age 10-11 were negatively associated with learning outcomes at that time, but interestingly, only for children with chronic illnesses. Perhaps relatedly, in the final model parenting consistency at age 6-7 also remained predictive of children's learning outcomes at age $10-11$.

In short, however, the child's approach to learning had the largest positive association with their learning outcomes. This is consistent with previous findings that report a child's adaptive competency, attitude and approach to learning are strongly associated with and predictive of their academic achievement, even after accounting for other well-known strong predictors such as SES (McNelis, Johnson, Huberty, \& Austin, 2005) and prior academic achievement (Duncan et al., 2007).

Our study also found that an inconsistent parenting style when children were aged 6-7 years influenced a child's academic performance in later childhood. For parents of children with a chronic illness this finding would appear particularly relevant as our analysis also found that parents of children with a chronic illness reported higher levels of parenting irritability and psychological stress than parents of children without a chronic illness. A similar finding also found by Gaspar de Matos (2013).Targeted programs to support parents of children with chronic 
illnesses that develop their coping, parenting skills, and knowledge and practices aimed at improving their child's approach to learning are warranted.

A single unexpected finding was in relation to a positive student-teacher relationship. Previous research has shown that a positive student-teacher relationship was associated with positive child academic achievement (Roorda et al., 2011), and this was also found to be the case at the univariate level in our study. However, when all other factors were taken in to account, a positive student-teacher relationship was associated to a small extent with poorer academic achievement. This finding could suggest that the relationship between these two variables may apply to a non-random portion of the sample, which implies a moderation effect (Baron \& Kenny, 1986), and is worthy of further exploration.

A strength of this study was that it used a nationally-representative sample to determine the risk and protective factors for child learning outcomes at a population-level. In addition, the broad range of factors considered encompassed the child's ecological environment at home and school, with the majority assessed using validated or well-accepted measures. A further strength was that each factor was examined both at school entry (age 6-7 years) and again at age 10-11 years, thereby taking in to account and controlling for concurrent predictors and potential confounders of child learning at age 10-11 years. This allowed for a more rigorous examination of the predictive strength of school entry factors on children's learning whilst taking in to account the influence of contemporaneous factors.

On one hand, a limitation of this study was that chronic illness was defined using a broadbased measure which does not distinguish nor reveal the differential results for specific 
conditions (e.g. cancer vs. asthma vs. hearing impairment). Specific diagnostic information about disabilities, health conditions or developmental disorders was not available in LSAC. However, our finding that $24.6 \%$ of children had a chronic health condition at school entry is consistent with the prevalence estimate in the United States of America (Van Cleave, Gortmaker, \& Perrin, 2010). Other research has shown that this broad-based measure captures a wide range of chronic illnesses from the more common (e.g. asthma, respiratory allergies, eczema and skin allergies, and repeated ear infections) to those that are less prevalent but can have a significant impact on a child's learning (e.g. epilepsy, diabetes, blood disorders, cystic fibrosis and sickle cell anemia) (Newacheck \& Taylor, 1992). Chronic illnesses can also be categorized according to those that can have either a direct or indirect impact on learning (Van Cleave et al., 2010). The direct impact category includes behavioural and learning difficulty conditions such as: developmental delay, learning disability, attention-deficit disorder and cerebral dysfunction. While those in the indirect category are described as physical conditions and include: heart problems, blood or respiratory disorders, epilepsy, and speech impairment. Nonetheless, it is widely accepted that a broad non-categorical approach is often considered more appropriate and relevant in health and education policy decision making as it takes into account the similarities of the functional impact and consequences of living with various chronic illnesses (Stein, 1993; van der Lee, Mokkink, Grootenhuis, Heymans, \& Offringa, 2007). Further, the fact that the broad-based measure includes a range of conditions of various prevalence, impact and direct or indirect association with learning outcomes, may mean that the importance of our findings, which are based on regression to the mean, for the chronic illness group could be understated in relation to those 
children with the more serious and impactful conditions, and, who are known, on average, to be at greater risk of disengagement from education and learning (Forrest, Bevans, Riley, Crespo, \& Louis, 2011; Newacheck \& Taylor, 1992).

This study provides the first comprehensive and longitudinal data on the risk and protective factors during children's transition to elementary school associated with later learning outcomes for both children with and without a chronic illness. While predictors were largely common for both groups of children, the final model was strongest for children with a chronic illness. Therefore, for children with a chronic illness, our findings provide evidence of the need for the development and provision of child and parent focused education programs that address the modifiable risk and protective factors identified in this study: the child's attitude and approach to learning and a consistent parenting style. 


\section{Key messages}

- Children with a chronic illness are at increased risk of poor learning and academic outcomes

- A family's socio-economic status and a child's past academic performance are well known predictors of children's future academic performance.

- This study adds to this knowledge that, for all children, but in particular for those with a chronic illness, their attitude and approach to learning during the period of their transition to school are predictive of academic performance in later childhood.

- Parents coping and parenting style during this period are also important and predictive factors.

- For children with a chronic illness, child focused education and parenting support interventions are warranted and may improve the future academic performance of these children. 


\section{References}

Australian Institute of Health and Welfare (AIHW. (2005). Selected chronic diseases among Australian's chidlren. Bulletin no. 29. Canberra, Australia: Australian Insitute of Health and Welfare.

Australian Institute of Family Studies. (2007). Growing Up in Australia: The Longitudinal Study of Australian Children. Retrieved from http://www.growingupinaustralia.gov.au/

Baron, R. M., \& Kenny, D. A. (1986). The Moderator -- Mediator Variable Distinction in Social Psychological Research: Conceptual, Strategic, and Statistical Considerations. Journal of Personality \& Social Psychology, 51(6), 1173-1182.

Brinkman, S., Gregory, T., Harris, J., Hart, B., Blackmore, S., \& Janus, M. (2013). Associations Between the Early Development Instrument at Age 5, and Reading and Numeracy Skills at Ages 8, 10 and 12: a Prospective Linked Data Study. CHILD INDICATORS RESEARCH, 6(4), 695-708.

Brooks-Gunn, J. (2003). Do you believe in magic? What we can expect from early childhood intervention programs. Social Policy Report, 17(1), 15.

Champaloux, S. W., \& Young, D. R. (2014). Original article: Childhood Chronic Health Conditions and Educational Attainment: A Social Ecological Approach. Journal of Adolescent Health. doi:10.1016/j.jadohealth.2014.07.016

Currie, J., \& Stabile, M. (2006). Child Mental Health and Human Capital Accumulation: The Case of ADHD. Journal of Health Economics, 25(6), 1094-1118. doi:http://www.sciencedirect.com/science/journal/01676296 
Running head: Predictors of learning outcomes for children with chronic illness

Daraganova, G., \& Sipthorp, M. (2011). Longitudinal Study of Australian Children: Technical Report 4. Retrieved from Melbourne:

Duncan, G. J., Dowsett, C. J., Claessens, A., Magnuson, K., Huston, A. C., Klebanov, P., Pagani, L., Feinstein, L., Engel, M, \& .Brooks-Gunn, J. (2007). School readiness and later achievement. Developmental Psychology, 43(6), 19.

EU-SILC 065. (2014). Methodological guidelines and description of EU-SILC target variables, 2014 operation. European Commission Retrieved from https://circabc.europa.eu/sd/a/2aa6257f-0e3c-4f1c-947f76ae7b275cfe/DOCSILC065\%20operation\%202014\%20VERSION\%20reconciliated\%20 and\%20early\%20transmission\%200ctober\%202014.pdf.

Forrest, C. B., Bevans, K. B., Riley, A. W., Crespo, R., \& Louis, T. A. (2011). School outcomes of children with special health care needs. Pediatrics, 128(2), 303-312.

Furukawa, T. A., Kessler, R. C., Slade, T., \& Andrews, G. (2003). The performance of the K6 and K10 screening scales for psychological distress in the Australian National Survey of Mental Health and Well-Being. Psychological medicine, 33(2), 357-362.

Gaspar de Matos, M. (2013). Do the Parent-Child Relationship and Parenting Behaviors Differ Between Families With a Child With and Without Chronic Illness? A Meta-Analysis. Journal of Pediatric Psychology, 38(7), 12.

Goodman, R. (2001). Psychometric properties of the strengths and difficulties questionnaire. Journal of the American Academy of Child \& Adolescent Psychiatry, 40(11), 1337-1345.

This article is protected by copyright. All rights reserved. 
Harper, P. (2010). ABS Sources of Disability Information, Australia 2003-2008. (4431.0.55.002).

Canberra: Australian Government Retrieved from http://www.ausstats.abs.gov.au/Ausstats/subscriber.nsf/0/69F4AB340D15511ACA25778 900119EC6/\$File/attqvre7.pdf.

Kuehni, C. E., Strippoli, M.-P. F., Rueegg, C. S., Rebholz, C. E., Bergstraesser, E., Grotzer, M., von der Weid, N., \& Michel, G. (2012). Educational achievement in Swiss childhood cancer survivors compared with the general population. Cancer, 18(5), 11.

Kyndt, E., Cascallar, E., \& Dochy, F. (2012). Individual differences in working memory capacity and attention, and their relationship with students' approaches to learning. Higher Education, 64(3), 285-297.

Li-Grining, C. P., Votruba-Drzal, E., Maldonado-Carreño, C., \& Haas, K. (2010). Children's early approaches to learning and academic trajectories through fifth grade. Developmental Psychology, 46(5), 1062.

Lum, A., Wakefield, C. E., Donnan, B., Burns, M. A., Fardell, J. E., \& Marshall, G. M. (2017). Understanding the school experiences of children and adolescents with serious chronic illness: a systematic meta-review. Child: Care, Health \& Development, 43(5), 645-662. doi:10.1111/cch.12475

Martinez, Y. J., \& Ercikan, K. (2009). Chronic illnesses in Canadian children: what is the effect of illness on academic achievement, and anxiety and emotional disorders? Child: Care, Health \& Development, 35(3), 391-401. doi:http://dx.doi.org/10.1111/j.1365$\underline{2214.2008 .00916 . x}$

This article is protected by copyright. All rights reserved. 
Maslow, G., Haydon, A. A., McRee, A.-L., \& Halpern, C. T. (2012). Protective Connections and Educational Attainment Among Young Adults With Childhood-Onset Chronic Illness*. Journal of School Health, 82(8), 364-370.

McNelis, A. M., Johnson, C. S., Huberty, T. J., \& Austin, J. K. (2005). Factors associated with academic achievement in children with recent-onset seizures. Seizure: European Journal of Epilepsy, 14, 331-339. doi:10.1016/j.seizure.2005.04.005

Muthén, L., \& Muthén, B. (2011). Mplus Users Guide. Los Angeles: Muthen \& Muthen.

Nasuuna, E., Santoro, G., Kremer, P., \& Silva, A. M. (2016). Examining the relationship between childhood health conditions and health service utilisation at school entry and subsequent academic performance in a large cohort of Australian children. Journal of Paediatrics and Child Health(7), 750. doi:10.1111/jpc.13183

Newacheck, P. W., \& Taylor, W. R. (1992). Childhood chronic illness: prevalence, severity, and impact. The American Journal of Public Health(3), 364.

O'Connor, M., Howell-Meurs, S., Kvalsvig, A., \& Goldfeld, S. (2015). Understanding the impact of special health care needs on early school functioning: a conceptual model. Child: Care, health and development, 41(1), 15-22.

Pianta, R. (2001). Student-Teacher Relationship Scale-Short Form. Lutz, FL: Psychological Assessment Resources, Inc.

Rock, D. A., \& Pollack, J. M. (2002). Early Childhood Longitudinal Study-Kindergarten Class of 1998-99 (ECLS-K): Psychometric Report for Kindergarten through First Grade. Working Paper Series.

This article is protected by copyright. All rights reserved. 
Roorda, D. L., Koomen, H. M., Spilt, J. L., \& Oort, F. J. (2011). The Influence of Affective Teacher-Student Relationships on Students' School Engagement and Achievement A Meta-Analytic Approach. Review of educational research, 81(4), 493-529.

Sektnan, M., McClelland, M. M., Acock, A., \& Morrison, F. J. (2010). Relations between early family risk, children's behavioral regulation, and academic achievement. Early Childhood Research Quarterly, 25(4), 464-479.

Shonkoff, J. P., \& Phillips, D. (2000). From neurons to neighborhoods. [electronic resource] : the science of early child development: Washington, D.C. : National Academy Press, c2000.

Singh, H., Nugent, Z., Brownell, M., Targownik, L. E., Roos, L. L., \& Bernstein, C. N. (2015). Original Article: Academic Performance among Children with Inflammatory Bowel Disease: A Population-Based Study. The journal of pediatrics, 166, 1128-1133. doi:10.1016/j.jpeds.2014.12.010

Soloff, C., Lawrence, D., \& Johnstone, R. (2005). LSAC technical reference paper number 1: sample design. Retrieved from Melbourne, Australia:

Statistics Canada. (1995). National Longitudinal Survey of Children: Survey Instruments for 1994-1995 Data Collection-Cycle 1. Retrieved from Ottawa, Canada:

Stein, R. E. K. (1993). Framework for identifying children who have chronic conditions - the case for a new definition. The journal of pediatrics, 122(3), 342.

This article is protected by copyright. All rights reserved. 
Running head: Predictors of learning outcomes for children with chronic illness

UK Office of National Statistics. (2015). Harmonised Concepts and Questions for Social Data Sources, Primary Principles: Long-lasting Health Conditions and Illnesses; Impairments and Disability. UK Office of National Statistics.

Van Cleave, J., Gortmaker, S. L., \& Perrin, J. M. (2010). Dynamics of obesity and chronic health conditions among children and youth. JAMA, The Journal of the American Medical $\operatorname{Association(7),623.~}$

van der Lee, J. H., Mokkink, L. B., Grootenhuis, M. A., Heymans, H. S., \& Offringa, M. (2007). Definitions and measurement of chronic health conditions in childhood: A systematic review. JAMA, 297(24), 2741-2751. doi:10.1001/jama.297.24.2741

Wiesner, M., Vondracek, F. W., Capaldi, D. M., \& Porfeli, E. (2003). Childhood and Adolescent Predictors of Early Adult Career Pathways. Journal of Vocational Behavior, 63(3), 305328.

This article is protected by copyright. All rights reserved. 
Table 1: Detailed description of predictors examined in multivariate analyses

\begin{tabular}{|c|c|c|c|}
\hline Construct & Measure & Reporter & Detail \\
\hline \multicolumn{4}{|l|}{ Child } \\
\hline Male $($ male $=1$, female $=2)$ & Child gender & Parent-reported & Single item \\
\hline $\begin{array}{l}\text { Emotional and behavioral } \\
\text { difficulties }\end{array}$ & $\begin{array}{l}\text { Strengths and } \\
\text { Difficulties } \\
\text { Questionnaire }\end{array}$ & Parent-reported & $\begin{array}{l}\text { a } 25 \text {-item validated measure of behavioral and } \\
\text { emotional problems for children aged } 4 \text { to } 16 \\
\text { years;(Goodman, 2001) } 20 \text { items contribute to the Total } \\
\text { Problems score used here (possible range } 0 \text { - } 40 \text {, with } \\
\text { higher scores representing poorer behavior/mental } \\
\text { health). }\end{array}$ \\
\hline Approach to learning & $\begin{array}{l}\text { Approach to Learning } \\
\text { subscale from the } \\
\text { Social Rating Scale }\end{array}$ & Teacher-reported & $\begin{array}{l}\text { A 6-item measure designed to assess various aspects of } \\
\text { a child's approach to learning, such as organization, } \\
\text { working independently and task completion. The } \\
\text { possible score range was } 1-6 \text {, with higher scores } \\
\text { indicating better approaches to learn.(Rock \& Pollack, } \\
\text { 2002) }\end{array}$ \\
\hline Days absent from School & & Teacher-reported & $\begin{array}{l}\text { Single item where teachers could indicate how many } \\
\text { days the student had been absent in the past month }\end{array}$ \\
\hline \multicolumn{4}{|l|}{ Family } \\
\hline Non-English Speaking & Study-item & Parent-reported & Yes / No \\
\hline Number of siblings & Study-item & Parent-reported & $\begin{array}{l}\text { Single item where parents could indicate the number of } \\
\text { related siblings in the household }\end{array}$ \\
\hline Two-parent family & Study-item & Parent-reported & Yes / No \\
\hline Socioeconomic position & & Parent-reported & $\begin{array}{l}\text { Composite standardized measure of parents' } \\
\text { occupational status, household income, and parents' } \\
\text { education; higher scores indicate more advantage }\end{array}$ \\
\hline
\end{tabular}

This article is protected by copyright. All rights reserved. 


\begin{tabular}{|c|c|c|c|}
\hline Construct & Measure & Reporter & Detail \\
\hline \multicolumn{4}{|l|}{ Parent } \\
\hline Maternal age at birth & & Parent-reported & \\
\hline Parenting anger & $\begin{array}{l}\text { National Longitudinal } \\
\text { Survey of Children } \\
\text { and Youth }\end{array}$ & Parent-reported & $\begin{array}{l}4 \text { items designed to measure the frequency with which } \\
\text { their interactions with the child entailed behaviors such } \\
\text { as disapproval, lack of praise, and anger (irritability, } \\
\text { e.g., "How often are you angry when you punish this } \\
\text { child?"). Responses were on 5-point Likert scales and } \\
\text { ranged from } 1 \text { ("never/almost never") to } 5 \text { ("all the } \\
\text { time"). Higher scores representing greater parenting } \\
\text { anger.(Statistics Canada, 1995) }\end{array}$ \\
\hline Parenting consistency & $\begin{array}{l}\text { National Longitudinal } \\
\text { Survey } \\
\text { of Children and Youth }\end{array}$ & Parent-reported & $\begin{array}{l}5 \text { items designed to address the frequency which they } \\
\text { set and enforced clear expectations and limits for their } \\
\text { children's behavior (control, e.g., "When you discipline } \\
\text { this child, how often does he/she ignore the } \\
\text { punishment?" reverse scored) Higher scores } \\
\text { representing higher parenting consistency.(Statistics } \\
\text { Canada, 1995) }\end{array}$ \\
\hline Parental mental distress & Kessler 6 & Self-reported & $\begin{array}{l}\text { a 6-item validated measure of mental health distress, } \\
\text { with higher scores indicating greater psychological } \\
\text { distress.(Furukawa, Kessler, Slade, \& Andrews, 2003) }\end{array}$ \\
\hline $\begin{array}{l}\text { Out of home learning } \\
\text { environment }\end{array}$ & $\begin{array}{l}\text { National Longitudinal } \\
\text { Survey of Children } \\
\text { and Youth (NLSCY) }\end{array}$ & Parent-reported & $\begin{array}{l}\text { 5-items designed to measure shared parent-child } \\
\text { activities outside of the home, with higher scores } \\
\text { representing more out of home activities(Statistics } \\
\text { Canada, 1995) }\end{array}$ \\
\hline $\begin{array}{l}\text { In home learning } \\
\text { environment }\end{array}$ & Home Activities Index & Parent-reported & $\begin{array}{l}\text { 7-items designed to measure the shared parent-child } \\
\text { activities in the home, with higher scores representing }\end{array}$ \\
\hline
\end{tabular}

This article is protected by copyright. All rights reserved. 


\begin{tabular}{|l|l|l|l|}
\hline Construct & Measure & Reporter & Detail \\
\hline Teacher / School & & better parent-child home learning interactions \\
\hline $\begin{array}{l}\text { Student-teacher } \\
\text { relationship }\end{array}$ & $\begin{array}{l}\text { Pianta Student- } \\
\text { Teacher Relationship } \\
\text { Scale (Short Form) }\end{array}$ & Teacher-reported & $\begin{array}{l}\text { A 14 items measure of the child's relationship with } \\
\text { their teacher with subscales for closeness and conflict. } \\
\text { The overall score is presented with higher scores } \\
\text { representing a more positive relationship with the } \\
\text { teacher.(Pianta, 2001) }\end{array}$ \\
\hline
\end{tabular}


Table 2: Socio-demographic characteristics for children with and without a chronic illness at wave 1

\begin{tabular}{|c|c|c|}
\hline Demographic characteristic & $\frac{\text { Children with a }}{\frac{\text { chronic illness }}{(n=987)}}$ & $\frac{\text { Children without a }}{\frac{\text { chronic illness }}{(\mathrm{n}=3023)}}$ \\
\hline & $\begin{array}{c}\mathrm{M}(\mathrm{SD}) \\
\text { or } \\
\mathrm{n}(\%)\end{array}$ & $\begin{array}{c}M(\mathrm{SD}) \\
\text { or } \\
\mathrm{n}(\%)\end{array}$ \\
\hline \multicolumn{3}{|l|}{ Child characteristics } \\
\hline Gender (Male) & $614(62.2 \%)$ & $1435(47.5 \%)$ \\
\hline $\operatorname{Age}(\mathrm{M}, \mathrm{SD})$ & $4.15(0.36)$ & $4.18(0.38)$ \\
\hline Born in Australia & $966(97.9 \%)$ & $2891(95.6 \%)$ \\
\hline Aboriginal or Torres Strait Islander & $36(3.6 \%)$ & $77(2.5 \%)$ \\
\hline Language other than English at home & $98(10.0 \%)$ & $422(14.0 \%)$ \\
\hline \multicolumn{3}{|l|}{ Family characteristics } \\
\hline Single parent family & $135(13.7 \%)$ & $314(10.4 \%)$ \\
\hline Number of siblings (M, SD) & $1.47(1.01)$ & $1.46(0.99)$ \\
\hline Socioeconomic position (M, SD) & $0.04(0.95)$ & $0.14(0.98)$ \\
\hline \multicolumn{3}{|l|}{ Mother characteristics } \\
\hline Maternal age at time of child's birth ( $<18$ years $)$ & $973(99.3 \%)$ & $2989(99.4 \%)$ \\
\hline Education level - Year 12 and above & $545(55.7 \%)$ & $1914(63.7 \%)$ \\
\hline In paid employment & $554(56.5 \%)$ & $1861(62.0 \%)$ \\
\hline \multicolumn{3}{|l|}{ Nature chronic illness } \\
\hline Sight problems & $42(4.3 \%)$ & \\
\hline Hearing problems & $81(8.2 \%)$ & \\
\hline Speech problems & $243(24.6 \%)$ & \\
\hline Blackouts, fits or loss of consciousness & $11(1.1 \%)$ & \\
\hline Difficulty learning or understanding & $52(5.3 \%)$ & \\
\hline Limited use of arms or fingers, legs or feet & $13(1.3 \%)$ & \\
\hline Disfigurement or deformity & $17(1.7 \%)$ & \\
\hline Has difficulty breathing & $35(3.5 \%)$ & \\
\hline Mental illness needing help or supervision & $9(0.9 \%)$ & \\
\hline Long term effects of head injury & $5(0.5 \%)$ & \\
\hline Other long-term or treated condition & $473(47.9 \%)$ & \\
\hline
\end{tabular}

This article is protected by copyright. All rights reserved. 
Running head: Predictors of learning outcomes for children with chronic illness

This article is protected by copyright. All rights reserved. 
Table 3: Multiple regression analyses of the risk and protective factors at age 6-7 for child learning at 10-11 years

\begin{tabular}{|c|c|c|c|c|}
\hline \multirow{2}{*}{\begin{tabular}{|l|} 
\\
Construct \\
\end{tabular}} & \multicolumn{2}{|c|}{$\frac{\text { Children with a chronic illness }}{(n=602)}$} & \multicolumn{2}{|c|}{$\frac{\text { Children without a chronic illness }}{(n=1915)}$} \\
\hline & Coefficient $(95 \% \mathrm{CI})$ & $\mathrm{p}$ & Coefficient $(95 \% \mathrm{CI})$ & $\mathrm{P}$ \\
\hline \multicolumn{5}{|l|}{ Child } \\
\hline Female & $0.02(-0.04$ to 0.07$)$ & .649 & $-0.03(-0.06$ to -0.01$)$ & .211 \\
\hline Emotional and behavioral difficulties & $-0.18(-0.26$ to 0.10$)$ & $<.001$ & $-0.09(-0.13$ to 0.04$)$ & .001 \\
\hline Approach to learning & $0.52(0.46$ to 0.52$)$ & $<.001$ & $0.37(0.33$ to 0.42$)$ & $<.001$ \\
\hline Days absent from school & $0.04(-0.02$ to 0.09$)$ & .287 & $-0.04(-0.08$ to 0.01$)$ & .083 \\
\hline \multicolumn{5}{|l|}{ Family } \\
\hline Non-English Speaking & $-0.01(-0.07$ to 0.06$)$ & .947 & $0.08(0.04$ to 0.12$)$ & .001 \\
\hline Number of siblings & $0.06(0.01$ to 0.11$)$ & .085 & $-0.05(-0.09$ to -0.01$)$ & .034 \\
\hline Two-parent family & $0.09(0.03$ to 0.14$)$ & .016 & $-0.02(-0.03$ to 0.06$)$ & .484 \\
\hline Socioeconomic position & $0.15(0.09$ to 0.22$)$ & $<.001$ & $0.22(0.18$ to 0.25$)$ & $<.001$ \\
\hline \multicolumn{5}{|l|}{ Parent } \\
\hline Mother was $<18$ years old at child's birth & $0.01(-0.06$ to 0.07$)$ & .923 & $0.03(-0.01$ to 0.07$)$ & .158 \\
\hline Parenting irritability/anger & $0.08(0.01$ to 0.14$)$ & .070 & $-0.01(-0.05$ to 0.04$)$ & .889 \\
\hline Parenting consistency & $0.11(0.04$ to 0.18$)$ & .007 & $0.07(0.03$ to 0.11$)$ & .005 \\
\hline Parental mental distress & $0.05(-0.02$ to 0.12$)$ & .211 & $0.05(0.01$ to 0.10$)$ & .055 \\
\hline Out of home learning environment & $0.01(-0.05$ to 0.07$)$ & .758 & $0.04(0.01$ to 0.07$)$ & .137 \\
\hline In home learning environment & $-0.10(-0.15$ to -0.04$)$ & .006 & $-0.08(-0.12$ to -0.05$)$ & $<.001$ \\
\hline \multicolumn{5}{|l|}{ Teacher/School } \\
\hline Student-teacher relationship & $-0.15(-0.22$ to -0.09$)$ & $<.001$ & $-0.08(-0.12$ to -0.04$)$ & .002 \\
\hline
\end{tabular}


Table 4: Multiple regression analyses of the risk and protective factors at age 6-7 for children's learning at 10-11 years whilst accounting for concurrent factors

\begin{tabular}{|c|c|c|c|c|}
\hline \multirow{2}{*}{ Construct } & \multicolumn{2}{|c|}{$\frac{\text { Children with a chronic illness }}{(\mathrm{n}=602)}$} & \multicolumn{2}{|c|}{$\frac{\text { Children without a chronic illness }}{(n=1915)}$} \\
\hline & Coefficient $(95 \% \mathrm{CI})$ & $\mathrm{p}$ & Coefficient $(95 \% \mathrm{CI})$ & $\mathrm{P}$ \\
\hline \multicolumn{5}{|l|}{ Child } \\
\hline Female & $-0.07(-0.13$ to -0.02$)$ & .028 & $-0.11(-0.14$ to -0.08$)$ & $<.001$ \\
\hline Emotional and behavioral difficulties at 6-7 yrs & $-0.04(-0.13$ to 0.04$)$ & .383 & $-0.02(-0.07$ to 0.02$)$ & .369 \\
\hline Emotional and behavioral difficulties at $10-11$ yrs & $-0.18(-0.27$ to -0.09$)$ & .001 & $-0.04(-0.08$ to -0.01$)$ & .179 \\
\hline Approach to learning at 6-7 yrs & $0.25(0.19$ to 0.32$)$ & $<.001$ & $0.20(0.16$ to 0.24$)$ & $<.001$ \\
\hline Approach to learning at $10-11$ yrs & $0.48(0.40$ to 0.55$)$ & $<.001$ & $0.46(0.42$ to 0.51$)$ & $<.001$ \\
\hline Days absent from school at 6-7 yrs & $0.05(-0.02$ to 0.11$)$ & .241 & $-0.03(-0.06$ to 0.00$)$ & .132 \\
\hline Days absent from school at $10-11$ yrs & $0.01(-0.05$ to 0.07$)$ & .719 & $0.01(-0.03$ to 0.04$)$ & .713 \\
\hline \multicolumn{5}{|l|}{ Family } \\
\hline Non-English Speaking & $-0.02(-0.07$ to 0.04$)$ & .613 & $0.06(0.03$ to 0.10$)$ & .004 \\
\hline Number of siblings & $0.03(-0.02$ to 0.08$)$ & .345 & $-0.05(-0.08$ to -0.01$)$ & .030 \\
\hline Two-parent family at 6-7 yrs & $0.05(-0.01$ to 0.10$)$ & .199 & $-0.03(-0.07$ to 0.01$)$ & .241 \\
\hline Two-parent family at 10-11 yrs & $-0.01(-0.06$ to 0.06$)$ & .988 & $0.02(-0.02$ to 0.06$)$ & .386 \\
\hline Socioeconomic position at 6-7 $\mathrm{yrs}^{\mathrm{a}}$ & $0.16(0.10$ to 0.22$)$ & $<.001$ & $0.16(0.13$ to 0.20$)$ & $<.001$ \\
\hline \multicolumn{5}{|l|}{ Parent } \\
\hline Mother was <18 years old at child's birth & $0.03(-0.02$ to 0.07$)$ & .304 & $0.03(-0.01$ to 0.06$)$ & .205 \\
\hline Parenting irritability/anger at 6-7 yrs & $0.04(-0.03$ to 0.11$)$ & .320 & $-0.02(-0.05$ to 0.04$)$ & .953 \\
\hline Parenting irritability/anger at $10-11$ yrs & $0.05(-0.02$ to 0.11$)$ & .263 & $0.02(-0.02$ to 0.07$)$ & .86 \\
\hline Parenting consistency at 6-7 yrs & $0.09(0.03$ to 0.16$)$ & .008 & $0.05(0.01$ to 0.09$)$ & .039 \\
\hline Parenting consistency at $10-11$ yrs & $0.02(-0.05$ to 0.09$)$ & .711 & $0.02(-0.02$ to 0.07$)$ & .366 \\
\hline Parental mental distress at 6-7 yrs & $0.05(-0.02$ to 0.11$)$ & .248 & $0.02(-0.02$ to 0.06$)$ & .380 \\
\hline Parental mental distress at $10-11$ yrs & $0.04(-0.07$ to 0.62$)$ & .920 & $0.02(-0.02$ to 0.05$)$ & .356 \\
\hline
\end{tabular}

This article is protected by copyright. All rights reserved. 
Out of home learning environment at 6-7 yrs

Out of home learning environment at 10-11 yrs

In home learning environment at 6-7 yrs

In home learning environment at 10-11 yrs

\section{Teacher/School}

Student-teacher relationship at 6-7 yrs

Student-teacher relationship at 10-11 yrs

$-0.10(-0.16$ to 0.03$)$

$0.01(-0.05$ to 0.07$)$

$0.01(-0.05$ to 0.06$)$

$-0.02(-0.08$ to -0.03$)$

$-0.15(-0.21$ to -0.09$)$

${ }^{a}$ SEP at 10-11 years was omitted from the multivariate model because it

\begin{tabular}{|c|c|c|c|}
\hline & .813 & & \\
\hline$)$ & .889 & & \\
\hline ) & .459 & & -0. \\
\hline ) & $<.001$ & & -0. \\
\hline$)$ & & & \\
\hline$)$ & 0.001 & & \\
\hline
\end{tabular}

\begin{tabular}{|c|c|}
\hline $0.02(-0.02$ to 0.06$)$ & .356 \\
\hline $0.05(0.01$ to 0.08$)$ & .022 \\
\hline$-0.06(-0.01$ to -0.03$)$ & .004 \\
\hline$-0.05(-0.08$ to -0.01$)$ & .028 \\
\hline$-0.05(-0.10$ to -0.0$)$ & $<.001$ \\
\hline$-0.05(-0.10$ to -0.01$)$ & .043 \\
\hline
\end{tabular}

(-0.05 (-0.10 to -0.01$)$

This article is protected by copyright. All rights reserved. 
[First Authors Last Name] Page 31

This article is protected by copyright. All rights reserved. 
Individual Level - Nature and severity of condition

- Socio-emotional and behavioural competencies - Learning competencies - Attitudes to schooling

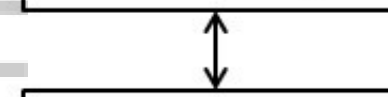

Family Level

- Socioeconomic status - Interaction with education and health service providers - Family resiliency

- Levels of support for and within the family

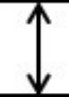

Service-systems Level - Information exchange and communication

- Assessment procedures

- Coordinated planning and

case management

- Policies and inclusiveness
Body Function \& Activities of

Structures

e.g. movement,

e.g. self-care, mobility

\section{Daily Living}

- School

engagement

- Bonding and

connectedness with

school

Educational

Participation

e.g. attendance,

integration into

programs

CCH_12597_F1.jpg 


\section{University Library}

\section{- M M N E R VA A gateway to Melbourne's research publications}

Minerva Access is the Institutional Repository of The University of Melbourne

Author/s:

Barnett, T;Giallo, R;Kelaher, M;Goldfeld, S; Quach, J

Title:

Predictors of learning outcomes for children with and without chronic illness: An Australian longitudinal study

Date:

2018-11-01

\section{Citation:}

Barnett, T., Giallo, R., Kelaher, M., Goldfeld, S. \& Quach, J. (2018). Predictors of learning outcomes for children with and without chronic illness: An Australian longitudinal study. CHILD CARE HEALTH AND DEVELOPMENT, 44 (6), pp.832-840. https://doi.org/10.1111/ cch.12597.

Persistent Link:

http://hdl.handle.net/11343/284142 